\title{
UJI EFEK ANTIBAKTERI EKSTRAK ETIL ASETAT DAN KLOROFORM MENIRAN (Phyllanthus niruri Linn) TERHADAP PERTUMBUHAN BAKTERI Staphylococcus aureus ATCC 6538 DAN Escherichia coli ATCC 11229 SECARA in vitro
}

\author{
Dwiariawan Tauchid Rahman, EM Sutrisna, Anika Candrasari \\ Fakultas Kedokteran, Universitas Muhammadiyah Surakarta \\ Correspondence to: Anika Candrasari \\ Email: Anika.Candrasari@ums.ac.id
}

\begin{abstract}
Meniran is one of traditional plants that contains several compounds such as terpenoid, flavonoid, and alkaloid that role as antibactrial agent. The aims of the research are to determine the antibacteria effect of extract aethyl acetat and chloroform of meniran. This research was conducted as a laboratory experimental by using post test control group design only. The concentration of extract aethyl acetat and chloroform meniran are $5 \%, 10 \%$, $20 \%, 40 \%$, and $80 \%$. The result indicate that extract aethyl acetat of meniran have not effect to Escherichia coli. Meanwhile, to Staphyloccus aureus have an effect $(p=0,003)$. The concentration of the extract chloroform meniran are effective to inhibite the growth of Escherichia coli $(p=0,029)$ and Staphylococcus aureus $(p=0,004)$. The extract aethyl acetat of meniran have an antibacteria effect to Staphylococcus aureus but not to Escherichia coli. Whereas, the extract chloroform of meniran have an antibacteria effect to Staphylococcus aureus and Escherichia coli.
\end{abstract}

Keyword : The aethyl acetat and chloroform extract of Meniran (Phyllanthus niruri L.), antibacteria effect, Staphylococcus aureus and Escherichia coli

\section{PENDAHULUAN}

Pemakaian herbal sebagai obat-obatan tradisional telah diterima luas di negara-negara maju maupun berkembang sejak dahulu kala, bahkan dalam 20 tahun terakhir perhatian dunia terhadap obat-obatan tradisional meningkat, baik di negara yang sedang berkembang maupun negara-negara maju. World Health Organization (WHO) atau Badan Kesehatan Dunia menyebutkan bahwa hingga $65 \%$ dari penduduk negara maju menggunakan pengobatan tradisional dan obatobat dari bahan alami (Kemenkes RI, 2007).

Indonesia merupakan negara besar yang terkenal karena keanekaragamannya, salah satunya adalah keanekaragaman hayati (megabiodiversity) khususnya tumbuhan. Selain itu Indonesia juga memiliki keanekaragaman etnis yang memiliki berbagai macam pengetahuan tentang obat tradisional yang menggunakan bahan-bahan dari tumbuhan. Banyak dari jenis tumbuhan itu telah ribuan tahun digunakan oleh nenek moyang bangsa Indonesia dan dokter sebagai bahan obat atau jamu tradisional untuk berbagai macam penyakit dan memberikan hasil yang baik bagi pemeliharaan kesehatan serta pengobatan (Mills, 1996). Di bumi ini diperkirakan terdapat 40.000 spesies tumbuhan. Dari jumlah tersebut sekitar 30.000 spesies hidup di kepulauan Indonesia dan sekurang-kurangnya 9.600 spesies diketahui berkhasiat obat, tetapi baru 300 spesies yang telah dimanfaatkan sebagai bahan baku obat tradisional dan industri obat tradisional (Kemenkes RI, 2007). Menteri Kesehatan melalui Surat Keputusan Menteri Kesehatan Republik Indonesia No.381/ MENKES/SK/III /2007 menetapkan kebijakan obat tradisional nasional (Kotranas) yang antara lain bertujuan untuk mendorong pemanfaatan sumber daya alam dan ramuan tradisional secara berkelanjutan (sustainable use) untuk digunakan dalam upaya peningkatan pelayanan kesehatan. 
Sebagai implementasi dari kebijakan tersebut Menteri Kesehatan melalui Peraturan Menteri Kesehatan No. 003/MENKES/PER/I/2010 tentang saintifikasi jamu dalam penelitian berbasis pelayanan kesehatan. Menurut peraturan tersebut pada pasal 1 diterangkan bahwa saintifikasi jamu adalah pembuktian ilmiah jamu melalui penelitian berbasis pelayanan kesehatan, sedangkan jamu diartikan sebagai obat tradisional Indonesia. Sementara itu obat tradisional adalah bahan atau ramuan yang berupa bahan tumbuhan, bahan hewan, bahan mineral, sediaan sarian (galenik), atau campuran dari bahan tersebut yang secara turun temurun telah digunakan untuk pengobatan, dan dapat diterapkan sesuai dengan norma yang ada.

Salah satu tanaman berkasiat obat Indonesia yang banyak digunakan di masyarakat adalah meniran (Phyllantus niruri Linn). Tumbuhan meniran banyak mengandung senyawa kimia yang memiliki berbagai macam khasiat, salah satu potensinya adalah sebagai antibakteri.

Menurut penelitian sebelumnya yang dilakukan oleh Gunawan, dkk (2008) telah berhasil menganalisis, mengisolasi, dan mengidentifikasi senyawa antibakteri di dalam tumbuhan ini. Senyawa yang dimaksud adalah senyawa terpenoid dengan metode Kromatografi Gas-Spektroskopi Massa. Hasil uji fitokimia menggunakan pereaksi Lieberman-Burchard tumbuhan meniran yang diekstraksi dengan menggunakan metode maserasi dan sohkletasi pelarut n-heksana menunjukkan bahwa kedua ekstrak tersebut positif mengandung senyawa terpenoid.

Harborne (1996) mengatakan bahwa secara kimia, terpenoid umumnya larut dalam lemak dan terdapat di dalam sitoplasma sel tumbuhan. Biasanya terpenoid diekstraksi dari jaringan tumbuhan dengan memakai eter minyak bumi, eter atau kloroform dan dapat dipisahkan secara kromatografi pada silika gel atau alumina memakai pelarut di atas. Pendapat ini berbeda dengan yang dilakukan oleh Gunawan, dkk (2008) di atas, sehingga sangat mungkin bahwa zat yang berhasil diisolasi berbeda konsentrasinya jika menggunakan metode Harborne (1996).

Berdasar pada latar belakang di atas, penelitian ini memiliki rumusan masalah "Apakah ada pengaruh konsentrasi ekstrak etil asetat dan kloroform tumbuhan meniran (Phyllantus niruri Linn) terhadap pertumbuhan bakteri Escherichia coli dan Staphylococcus aureus?"
Adapun tujuan dari penelitian ini adalah untuk mengetahui daya antibakteri ekstrak etil asetat dan kloroform tumbuhan meniran (Phyllantus niruri Linn) terhadap pertumbuhan bakteri Escherichia coli dan Staphylococcus aureus.

Manfaat dari penelitian ini secara teoritis adalah menambah serta mendukung perkembangan ilmu pengetahuan kesehatan khususnya di bidang fitofarmaka dan secara praktis akan diperoleh informasi ekstrak etil asetat dan kloroform tumbuhan meniran (Phyllantus niruri Linn) terhadap bakteri Escherichia coli dan Staphylococcus aureus. Informasi ini sebagai salah satu bukti empirik yang dapat digunakan sebagai landasan ilmiah untuk sosialisasi dan pemasyarakatan tumbuhan obat Indonesia serta saintifikasi tanaman obat, khususnya tumbuhan meniran (Phyllantus niruri Linn).

\section{METODE PENELITIAN}

Penelitian ini bersifat eksperimental laboratorik dengan metode post test control group design only. Penelitian dilaksanakan di Lab. Biomedik II Sub Lab. Mikrobiologi FK UMS pada bulan Juli - Oktober 2011 dengan subjek penelitian tumbuhan meniran (Phyllantus niruri Linn) yang telah dideterminasi di Lab. Biologi FKIP UMS. Tumbuhan meniran diekstraksi dengan pelarut etil asetat dan kloroform masing-masing dengan konsentrasi 5\%, 10\%, 20\%, 40\%, dan 80\% di Lab. Biomedik III Sub Lab. Farmakologi FK UMS.

Menurut Harmita dan Radji (2004) konsentrasi atau dosis berturut-turut dapat diperoleh dengan rumus Progresi Geometris.

$$
\mathbf{Y}_{\mathrm{N}}=\mathbf{Y}_{1} \mathbf{R}^{\mathrm{N}-1}
$$

Keterangan :

$\mathrm{Y}_{\mathrm{N}}=$ dosis ke-n merupakan dosis pertama

$\mathrm{R}^{\mathrm{N}-1}=$ merupakan faktor pemacu

$\mathrm{N}=$ dosis deret pertama berikut:

Maka perhitungannya adalah sebagai

1. Konsentrasi $1=5 \%$

2. Konsentrasi $2=10 \%$

3. Konsentrasi $3=20 \%$

4. Konsentrasi $4=40 \%$

5. Konsentrasi $5=80 \%$ 
Sementara itu bakteri uji yang digunakan adalah Escherichia coli ATCC 11229 dan Staphylococcus aureus ATCC 6538, merupakan bakteri uji sensitif dan biakan murni yang diperoleh dari Lab. Biomedik II Sub Lab. Mikrobiologi FK UMS.

Variabel independen (bebas) adalah ekstrak kloroform dan ekstrak etil asetat tumbuhan meniran (Phyllantus niruri Linn). Variabel dependen (terikat) adalah efek antibakteri terhadap pertumbuhan bakteri uji (Escherichia coli ATCC 11229 dan Staphylococcus aureus ATCC 6538). Pengujian efek antibakteri menggunakan teknik difusi sumuran dengan diameter sumur $6 \mathrm{~mm}$. Efek antibakteri di ukur dari diameter Zona Hambat (zona jernih) dengan satuan ukur milimeter ( $\mathrm{mm}$ ) pada masing-masing konsentrasi ekstrak etil asetat dan kloroform tumbuhan meniran (Phyllantus niruri Linn) terhadap pertumbuhan bakteri uji.

Variabel luar yang terkendali yaitu asal tanaman, media Muller Hinton agar, pH, waktu inkubasi, suhu, dan kelarutan ekstrak. Sedangkan variabel luar yang tak terkendali adalah metabolisme kuman, umur tumbuhan, dan musim.

Bahan utama yang digunakan adalah tumbuhan meniran (Phyllantus niruri Linn) dengan bahan penyari etil asetat, kloroform, dan aquadest steril. Bahan uji efek antibakteri menggunakan media Muller Hinton agar, Blood Agar Plate (BAP), McConkey agar, Brain Heart Infusion (BHI), Aqubidest steril, Standar McFarland, $\mathrm{NaCl}$ fisiologis, antibiotik Amoxicilin $500 \mathrm{mg}$ dan Kloramfenikol $250 \mathrm{mg}$, suspending agent Dimetilsulfoksida (DMSO) $0,5 \%$.

Diameter zona hambat pertumbuhan Escherichia coli ATCC 11229 dan Staphylococcus aureus ATCC 6538 dalam berbagai konsentrasi ekstrak etil asetat dan kloroform di uji dengan metode sumuran. Metode ini umum digunakan dalam uji efek antibakteri karena lebih efektif untuk menghambat pertumbuhan bakteri dan zat aktif dapat berdifusi langsung tanpa penghalang kertas cakram (seperti pada metode Kirby Bauer yang menggunakan kertas cakram). Selain itu, dengan metode ini dapat diketahui luas zona hambat. Diameter zona hambat merupakan petunjuk kepekaan bakteri uji. Semakin besar zona hambat maka daya antibakteri yang semakin baik (Panagan \& Syarif, 2009).

Kontrol positif Amoxicilin dan Kloramfenikol yang digunakan dibuat dengan konsentrasi $100 \%$ sehingga memberikan diameter zona hambatan cukup besar, masing-masing 60 $\mathrm{mm}$ dan $50 \mathrm{~mm}$.

\section{HASIL DAN PEMBAHASAN}

Hasil pengujian daya hambat berbagai konsentrasi ekstrak etil asetat tumbuhan meniran terhadap bakteri Escherichia coli ATCC 11229 yang disajikan pada tabel 1 menunjukkan bahwa bahwa tidak terdapat efek antibakteri pada kontrol negatif dan tiap-tiap konsentrasi ekstrak etil asetat tumbuhan meniran terhadap bakteri Escherichia coli.

Tabel 2 menunjukkan bahwa ekstrak etil asetat tumbuhan meniran dengan konsentrasi $5 \%$ dan $10 \%$ tidak mempunyai efek antibakteri terhadap bakteri Staphylococcus aureus ATCC 6538. Zona hambat pada Staphylococcus aureus ATCC 6538 terbentuk pada konsentrasi 20\%, $40 \%$, tetapi diameter tersebut lebih kecil jika dibandingkan dengan diameter kontrol positif (Amoxicilin).

Sementara ekstrak etil asetat baru berpengaruh terhadap pertumbuhan bakteri Staphylococcus aureus pada konsentrasi 20\%, $40 \%$, dan $80 \%$, sementara $5 \%$ dan $10 \%$ tidak menunjukkan daya hambat. Hal ini dapat dijelaskan bahwa konsentrasi ekstrak etil asetat yaitu 5\% dan $10 \%$ memiliki konsentrasi yang kecil sehingga belum mampu menyebabkan terjadinya perubahan sistem fisiologis sel bakteri uji, sehingga bakteri masih dapat tumbuh (Darmayasa, 2008). Hal ini terbukti ketika konsentrasi ditambah, daya hambat mulai tampak yaitu pada konsentrasi $20 \%, 40 \%$, dan $80 \%$.

Peningkatan konsentrasi, tentu akan diikuti dengan peningkatan konsentrasi zat bioaktif, sehingga efek antibakterinya makin tinggi pula. Hal ini ditandai dengan bertambahnya diameter zona hambat. Sementara itu peningkatan konsentrasi dari $40 \%$ ke $80 \%$ tidak menunjukkan peningkatan yang signifikan zona hambat. Dengan perkataan lain pada konsentrasi $80 \%$ zona hambat yang terbentuk lebih kecil dibandingkan dengan konsentrasi $40 \%$. Hal ini dapat disebabkan oleh karena kepekatan stok konsentrasi $80 \%$ yang lebih pekat sehingga mengurangi daya difusi pada media Muller Hinton agar. Dengan demikian meskipun konsentrasi bertambah, tetapi banyaknya zat bioaktif yang dapat berdifusi ke dalam medium lebih sedikit, sehingga pengaruhnya pada pembentukan zona hambat juga sedikit. 
Tabel 3 menunjukkan bahwa ekstrak kloroform konsentrasi 5\%, 10\%, 20\%, 40\%, dan $80 \%$ masing-masing memiliki zona hambat terhadap bakteri Escherichia coli, yang terbesar terdapat pada konsentrasi $40 \%$. Dari tabel 4 didapatkan data zona hambat pada kelompok perlakuan konsentrasi ekstrak kloroform mulai konsentrasi 5\%, 10\%, 20\%, 40\%, dan 80\% dengan zona hambat terbesar terdapat pada konsentrasi $80 \%$.

Tabel 1. Hasil Pengujian Ekstrak Etil Asetat Tumbuhan Meniran dengan Berbagai Konsentrasi terhadap Bakteri Escherichia coli ATCC 11229 (mm)

\begin{tabular}{|c|c|c|c|c|c|c|c|}
\hline \multirow{3}{*}{ Replikasi } & \multicolumn{7}{|c|}{$\begin{array}{c}\text { Diameter Zona Hambat } \\
\text { Bakteri Escherichia coli ATCC } 11229(\mathrm{~mm})\end{array}$} \\
\hline & \multirow{2}{*}{$\begin{array}{c}\text { Kontrol (-) } \\
\text { Aquades Steril }\end{array}$} & \multirow{2}{*}{$\begin{array}{l}\text { Kontrol }(+) \\
\text { Kloramfenikol }\end{array}$} & \multicolumn{5}{|c|}{ Ekstrak Etil Asetat Tumbuhan Meniran } \\
\hline & & & $\begin{array}{l}5 \% \\
b / v\end{array}$ & $\begin{array}{l}10 \% \\
\mathrm{~b} / \mathrm{v}\end{array}$ & $\begin{array}{c}20 \% \\
\mathrm{~b} / \mathrm{v}\end{array}$ & $\begin{array}{l}40 \% \\
b / v\end{array}$ & $\begin{array}{l}80 \% \\
\mathrm{~b} / \mathrm{V}\end{array}$ \\
\hline 1 & 6 & 50 & 6 & 6 & 6 & 6 & 6 \\
\hline 2 & 6 & 50 & 6 & 6 & 6 & 6 & 6 \\
\hline 3 & 6 & 50 & 6 & 6 & 6 & 6 & 6 \\
\hline
\end{tabular}

Tabel 2. Hasil Pengujian Ekstrak Etil Asetat Tumbuhan Meniran dengan Berbagai Konsentrasi terhadap Bakteri Staphylococcus aureus ATCC 6538 (mm)

\begin{tabular}{|c|c|c|c|c|c|c|c|}
\hline \multirow{3}{*}{ Replikasi } & \multicolumn{7}{|c|}{$\begin{array}{c}\text { Diameter Zona Hambat } \\
\text { Bakteri Staphylococcus aureus ATCC } 6538(\mathrm{~mm})\end{array}$} \\
\hline & \multirow{2}{*}{$\begin{array}{c}\text { Kontrol (-) } \\
\text { Aquades Steril }\end{array}$} & \multirow{2}{*}{$\begin{array}{l}\text { Kontrol }(+) \\
\text { Amoxicilin }\end{array}$} & \multicolumn{5}{|c|}{$\begin{array}{l}\text { Ekstrak Etil Asetat } \\
\text { Tumbuhan Meniran }\end{array}$} \\
\hline & & & $\begin{array}{l}5 \% \\
b / v\end{array}$ & $\begin{array}{l}10 \% \\
\mathrm{~b} / \mathrm{v}\end{array}$ & $\begin{array}{c}20 \% \\
\mathrm{~b} / \mathrm{v}\end{array}$ & $\begin{array}{l}40 \% \\
\mathrm{~b} / \mathrm{v}\end{array}$ & $\begin{array}{l}80 \% \\
b / v\end{array}$ \\
\hline 1 & 6 & 60 & 6 & 6 & 8 & 14 & 12 \\
\hline 2 & 6 & 60 & 6 & 6 & 10 & 13 & 11 \\
\hline 3 & 6 & 60 & 6 & 6 & 10 & 14 & 11 \\
\hline Rata-rata & 6 & 60 & 6 & 6 & 9,3 & 13,6 & 11,3 \\
\hline
\end{tabular}

Tabel 3. Hasil Pengujian Ekstrak Kloroform Tumbuhan Meniran dengan Berbagai Konsentrasi terhadap Bakteri Escherichia coli ATCC 11229 (mm)

\begin{tabular}{|c|c|c|c|c|c|c|c|}
\hline \multirow{3}{*}{ Replikasi } & \multicolumn{7}{|c|}{$\begin{array}{c}\text { Diameter Zona Hambat } \\
\text { Bakteri Escherichia coli ATCC } 11229(\mathrm{~mm})\end{array}$} \\
\hline & \multirow{2}{*}{$\begin{array}{l}\text { Kontrol (-) } \\
\text { DMSO }\end{array}$} & \multirow{2}{*}{$\begin{array}{l}\text { Kontrol }(+) \\
\text { Kloramfenikol }\end{array}$} & \multicolumn{5}{|c|}{$\begin{array}{l}\text { Ekstrak Kloroform } \\
\text { Tumbuhan Meniran }\end{array}$} \\
\hline & & & $\begin{array}{l}5 \% \\
b / v\end{array}$ & $\begin{array}{l}10 \% \\
\mathrm{~b} / \mathrm{v}\end{array}$ & $\begin{array}{l}20 \% \\
b / v\end{array}$ & $\begin{array}{l}40 \% \\
\mathrm{~b} / \mathrm{v}\end{array}$ & $\begin{array}{l}80 \% \\
\mathrm{~b} / \mathrm{v}\end{array}$ \\
\hline 1 & 6 & 50 & 11 & 6 & 12 & 12 & 8 \\
\hline 2 & 6 & 50 & 6 & 10 & 9 & 11 & 6 \\
\hline 3 & 6 & 50 & 8 & 9 & 6 & 10 & 6 \\
\hline Rata-rata & 6 & 50 & 8,3 & 8,3 & 9 & 11 & 6,6 \\
\hline
\end{tabular}

Tabel 4. Hasil Pengujian Ekstrak Kloroform Tumbuhan Meniran dengan Berbagai Konsentrasi terhadap Daya Hambat Pertumbuhan Bakteri Staphylococcus aureus ATCC 6538 setelah 24 jam

\begin{tabular}{|c|c|c|c|c|c|c|c|}
\hline \multirow{3}{*}{ Replikasi } & \multicolumn{7}{|c|}{$\begin{array}{c}\text { Diameter Zona Hambat } \\
\text { Bakteri Staphylococcus aureus ATCC } 6538(\mathrm{~mm}) \\
\end{array}$} \\
\hline & \multirow{2}{*}{$\begin{array}{l}\text { Kontrol (-) } \\
\text { DMSO }\end{array}$} & \multirow{2}{*}{$\begin{array}{l}\text { Kontrol }(+) \\
\text { Amoxicilin }\end{array}$} & \multicolumn{5}{|c|}{$\begin{array}{c}\text { Ekstrak Kloroform } \\
\text { Tumbuhan Meniran }\end{array}$} \\
\hline & & & $\begin{array}{l}5 \% \\
\mathrm{~b} / \mathrm{v}\end{array}$ & $\begin{array}{l}10 \% \\
\mathrm{~b} / \mathrm{v}\end{array}$ & $\begin{array}{l}20 \% \\
\mathrm{~b} / \mathrm{v}\end{array}$ & $\begin{array}{l}40 \% \\
\mathrm{~b} / \mathrm{v}\end{array}$ & $\begin{array}{c}80 \% \\
\mathrm{~b} / \mathrm{V}\end{array}$ \\
\hline 1 & 6 & 60 & 10 & 12 & 20 & 22 & 24 \\
\hline 2 & 6 & 60 & 10 & 12 & 16 & 17 & 27 \\
\hline 3 & 6 & 60 & 11 & 14 & 21 & 25 & 27 \\
\hline Rata-rata & 6 & 60 & 10,3 & 12,6 & 19 & 21,3 & 26 \\
\hline
\end{tabular}


Tabel 5. Hasil Uji Non Parametrik Mann Whitney Ekstrak Etil Asetat Meniran terhadap Bakteri Staphylococcus aureus ATCC 6538

\begin{tabular}{ccc}
\hline Kelompok Perlakuan & $\mathrm{P}$ & Hasil Uji \\
\hline Kontrol (-) - konsentrasi 5\% & 1,000 & Tak berbeda nyata \\
Kontrol (-) - konsentrasi 10\% & 1,000 & Tak berbeda nyata \\
Kontrol (-) - konsentrasi 20\% & 1,000 & Tak berbeda nyata \\
Kontrol (-) - konsentrasi 40\% & 0,034 & Berbeda bermakna \\
Kontrol (-) - konsentrasi 80\% & 0,034 & Berbeda bermakna \\
Kontrol (+) - konsentrasi 5\% & 0,025 & Berbeda bermakna \\
Kontrol (+) - konsentrasi 10\% & 0,025 & Berbeda bermakna \\
Kontrol $(+)$ - konsentrasi 20\% & 0,034 & Berbeda bermakna \\
Kontrol $(+)$ - konsentrasi 40\% & 0,034 & Berbeda bermakna \\
Kontrol (+) - konsentrasi 80\% & 0,034 & Berbeda bermakna \\
\hline
\end{tabular}

Berdasarkan hasil uji lanjut, pada data pada Tabel 5 di atas, dapat disimpulkan bahwa (1) tidak terdapat perbedaan nyata antara kontrol negatif dengan perlakuan beberapa macam konsentrasi ekstrak etil asetat meniran 5\%, 10\%, dan $20 \%$. Dengan perkataan lain tidak terdapat efek hambatan ekstrak etil asetat meniran 5\%,10\%,20\% terhadap pertumbuhan bakteri Staphylococcus aureus. (2) Efek hambatan terdapat pada konsentrasi $40 \%$ dan $80 \%$. Rerata zona hambatan pada ekstrak konsentrasi $40 \%$ lebih besar dari pada $80 \%$. Atas dasar itu konsentrasi esktrak etil asetat $40 \%$ lebih efektif untuk menghambat pertumbuhan bakteri Staphylococcus aureus.

Tabel 6. Hasil Uji Non Parametrik Mann Whitney Ekstrak Kloroform Meniran terhadap Bakteri Escherichia coli ATCC 11229

\begin{tabular}{ccl}
\hline Kelompok Perlakuan & P & Hasil Uji \\
\hline Kontrol (-) - konsentrasi 5\% & 0,121 & Tak berbeda nyata \\
Kontrol (-) - konsentrasi 10\% & 0,121 & Tak berbeda nyata \\
Kontrol (-) - konsentrasi 20\% & 0,121 & Tak berbeda nyata \\
Kontrol (-) - konsentrasi 40\% & 0,037 & berbeda bermakna \\
Kontrol (-) - konsentrasi 80\% & 0,317 & Tak berbeda nyata \\
Kontrol (+) - konsentrasi 5\% & 0,037 & Berbeda bermakna \\
Kontrol (+) - konsentrasi 10\% & 0,037 & Berbeda bermakna \\
Kontrol (+) - konsentrasi 20\% & 0,037 & Berbeda bermakna \\
Kontrol (+) - konsentrasi 40\% & 0,037 & Berbeda bermakna \\
Kontrol (+) - konsentrasi 80\% & 0,034 & Berbeda bermakna \\
\hline
\end{tabular}

Berdasarkan hasil uji lanjut, pada data pada Tabel 6 di atas, dapat disimpulkan bahwa (1) Tidak terdapat perbedaan nyata antara kontrol negatif dengan perlakuan beberapa macam konsentrasi ekstrak etil asetat meniran $5 \%, 10 \%$, dan $20 \%$, serta $80 \%$. Dengan perkataan lain tidak terdapat efek hambatan ekstrak kloroform meniran 5\%, $10 \%, 20 \%$, dan $80 \%$ terhadap pertumbuhan bakteri Escherichia coli. (2) Efek hambatan terdapat pada konsentrasi $40 \%$. Atas dasar itu konsentrasi esktrak kloroform $40 \%$ efektif untuk menghambat pertumbuhan Escherichia coli. 
Tabel 7. Hasil Uji Non Parametrik Mann Whitney Ekstrak Kloroform Meniran terhadap Bakteri Staphylococcus aureus ATCC 6538

\begin{tabular}{ccl}
\hline Kelompok Perlakuan & P & Hasil Uji \\
\hline Kontrol (-) - konsentrasi 5\% & 0,034 & Berbeda bermakna \\
Kontrol (-) - konsentrasi 10\% & 0,034 & Berbeda bermakna \\
Kontrol (-) - konsentrasi 20\% & 0,037 & Berbeda bermakna \\
Kontrol (-) - konsentrasi 40\% & 0,037 & Berbeda bermakna \\
Kontrol (-) - konsentrasi 80\% & 0,034 & Berbeda bermakna \\
Kontrol (+) - konsentrasi 5\% & 0,034 & Berbeda bermakna \\
Kontrol (+) - konsentrasi 10\% & 0,034 & Berbeda bermakna \\
Kontrol $(+)$ - konsentrasi 20\% & 0,037 & Berbeda bermakna \\
Kontrol $(+)$ - konsentrasi 40\% & 0,037 & Berbeda bermakna \\
Kontrol $(+)$ - konsentrasi 80\% & 0,034 & Berbeda bermakna \\
\hline
\end{tabular}

Berdasarkan hasil uji lanjut, pada data pada Tabel 7 di atas, dapat disimpulkan bahwa terdapat perbedaan yang signifikan untuk setiap penambahan konsentrasi ekstrak

Perbedaan zona hambat yang terjadi pada bakteri Staphylococcus aureus dan Escherichia coli disebabkan karena adanya perbedaan struktur dinding sel antara kedua bakteri yang mempengaruhi kerja ekstrak etil asetat sebagai senyawa antibakteri. Artinya ekstrak etil asetat tumbuhan meniran baru dapat menimbulkan efek jika ekstrak tersebut dapat masuk ke dalam sel bakteri yang diuji. Struktur dinding sel bakteri Gram positif lebih sederhana, yaitu berlapis tunggal dengan kandungan lipid yang rendah sehingga memudahkan bahan bioaktif masuk kedalam sel (Salni et al, 2011). Staphylococcus aureus sebagai bakteri gram positif memiliki 3 lapisan yaitu selaput sitoplasma, lapisan peptidoglikan yang tebal dan simpai (Jawetz et al, 2001).

Sementara struktur dinding sel bakteri gram negatif lebih kompleks, berlapis tiga, yaitu lapisan luar lipoprotein, lapisan tengah liposakarida yang berperan sebagai penghalang masuknya bahan bioaktif antibakteri, dan lapisan dalam berupa petidoglikan dengan kandungan lipid tinggi (Salni et al, 2011). Escherichia coli sebagai gram negatif memiliki lapisan yang lebih kompleks dan berlapis-lapis yaitu selaput sitoplasma, lapisan tunggal peptidoglikan dan selaput luar yang terdiri dari lipoprotein dan lipopolisakarida. Adanya perbedaan struktur dan komponen dinding sel tersebut yang menyebabkan Escherichia coli sebagai gram negatif lebih resisten (Jawetz et al, 2001) dibandingkan dengan Staphylococcus aureus.

Berdasarkan pada hasil-hasil tersebut efek antibakteri ekstrak kloroform terhadap pembentukan zona hambat berpengaruh pada kedua bakteri. Pengaruh ekstrak kloroform terhadap Escherichia coli juga lebih tampak meskipun struktur dinding sel bakteri ini lebih kompleks. Hal ini dapat dijelaskan kemungkinan pada ekstrak kloroform mengandung zat utama alkaloid dan terpenoid yang berpengaruh masingmasing menghambat sintesis dinding sel dan mengubah permeabilitas membran sel (Robinson, 2005) walaupun tidak hanya zat-zat tersebut saja yang mungkin terkandung dalam ekstrak kloroform tumbuhan meniran, sementara ekstrak etil asetat kemungkinan mengandung flavonoid sehingga diduga hanya memiliki mekanisme antibakteri dengan cara pengubahan permeabilitas membran sel.

Efek antibakteri ekstrak kloroform tumbuhan meniran tampak terhadap bakteri Staphylococcus aureus. Hal ini dapat terjadi karena kemungkinan didukung oleh dua faktor utama, yaitu (1) kandungan ekstrak kloroform tumbuhan meniran terdiri atas dua macam zat yang berpengaruh ganda terhadap sel bakteri, yaitu mengubah permeabilitas membran sel dan yang kedua menghambat sintesis dinding sel. Kedua proses ini membantu mempercepat masuknya zat bioaktif ke dalam sel dan menganggu metabolisme sel sehingga menyebabkan kematian pada sel. (2) Struktur dinding sel bakteri Staphylococcus aureus tergolong lebih sederhana jika dibandingkan 
dengan struktur dinding sel bakteri gram negatif seperti Escherichia coli, sehingga efek antibakteri yang diberikan lebih nyata.

Menurut Kardinan dan Kusuma (2004) dalam Gunawan dkk (2008) herba meniran mengandung metabolit sekunder seperti flavonoid, terpenoid, alkaloid, dan steroid. Beberapa hasil penelitian menunjukkan senyawa terpenoid memiliki aktivitas sebagai antibakteri yaitu monoterpenoid linalool, diterpenoid (-) hardwicklic acid, phytol, triterpenoid saponin, dan triterpenoid glikosida. Sebagai perbandingan penelitian identifikasi senyawa aktif antibakteri herba meniran yang dilakukan oleh Gunawan dkk (2008), tumbuhan meniran diekstraksi dengan metanol dan diidentifikasi senyawa-senyawa aktif antibakteri dari herba meniran tersebut. Hasil yang didapatkan ekstrak yang mengandung senyawa terpenoid memberikan daya hambat antibakteri yang lebih baik. Fraksi yang mengandung senyawa terpenoid (diterpenoid) tersebut diuji pada bakteri Staphylococcus aureus ATCC 25923 dan membentuk zona hambat sebesar $19 \mathrm{~mm}$ sedangkan fraksi lain membentuk diameter zona hambat sebesar $12 \mathrm{~mm}$. Penelitian lain yang dilakukan oleh Manguwardoyo dkk (2008), herba meniran di ekstrak dengan metode maserasi dan refluk menggunakan pelarut etanol $96 \%$, etil asetat, dan n-heksan kemudian diuji efek antijamur dan antibakteri dengan metode difusi dan dilusi. Hasil yang didapatkan ekstrak etanol $96 \%$ pada konsentrasi $96-288 \mathrm{mg} / \mathrm{ml}$ dapat menghambat pertumbuhan bakteri gram positif Staphylococcus aureus, sedangkan ekstrak etil asetat dan n-heksan tidak memberikan daya hambat terhadap jamur dan bakteri. Penelitian uji aktivitas antibakteri herba meniran yang dilakukan oleh Mangunwardoyo dkk (2008) memiliki kesamaan dengan penelitian ini dimana ekstrak herba meniran yang diuji cenderung memiliki aktivitas antibakteri pada bakteri gram positif yakni Staphylococcus aureus dan tidak memiliki aktivitas antibakteri terhadap gram negatif Escherichia coli.

Penelitian uji efek antibakteri tumbuhan meniran ini masih terbatas pada pengekstrakan bahan tanaman dengan pelarut yang kemudian diuji efek antibakterinya tetapi tidak dilakukan identifikasi lebih lanjut terhadap senyawasenyawa yang terlarut dalam ekstrak tersebut. Sehingga belum dapat dipastikan senyawa mana yang benar-benar memiliki efek antibakteri pada ekstrak etil asetat dan ekstrak kloroform tumbuhan meniran. Selain itu bakteri uji yang digunakan pada penelitian ini merupakan bakteri uji sensitif, sedangkan masalah yang terjadi di masyarakat adalah resistensi bakteri terhadap antibiotik.

\section{KESIMPULAN}

Terdapat efek antibakteri konsentrasi ekstrak etil asetat 20\%, 40\%, 80\% tumbuhan meniran (Phyllantus niruri Linn) terhadap bakteri Staphylococcus aureus ATCC 6538 serta konsentrasi ekstrak kloroform 5\%, 10\%, 20\%, 40\%, 80\% tumbuhan meniran (Phyllantus niruri Linn) terhadap bakteri Staphylococcus aureus ATCC 6538.

Tetapi ekstrak etil asetat tumbuhan meniran tidak menunjukkan pengaruh terhadap bakteri Escherichia coli ATCC 11229. Konsentrasi ekstrak kloroform 40\% efektif menghambat bakteri Escherichia coli ATCC 11229.

Terdapat perbedaan efek antibakteri konsentrasi ekstrak etil asetat dan kloroform. Konsentrasi ekstrak etil asetat hanya berpengaruh pada pertumbuhan bakteri Staphylococcus aureus sedangkan konsentrasi ekstrak kloroform berpengaruh pada pertumbuhan bakteri Escherichia coli dan Staphylococcus aureus.

\section{SARAN}

Perlu dilakukan identfikasi lebih lanjut senyawa-senyawa aktif pada ekstrak etil asetat dan kloroform tumbuhan meniran (Phyllantus niruri Linn) dan penelitian lebih lanjut mengenai efektivitas antibakteri tumbuhan meniran (Phyllantus niruri Linn) dengan menggunakan pelarut, metode ekstraksi, maupun bakteri uji yang lain.

\section{DAFTAR PUSTAKA}

Gunawan, I W. G., Gede Bawa, I G. A., Sutrisnayanti, N. L., 2008. Isolasi dan Identifikasi Senyawa Terpenoid yang Aktif Antibakteri pada Herba Meniran (Phyllanthus niruri Linn). Jurusan Kimia FMIPA Universitas Udayana. Jurnal Kimia 2 (1), Januari 2008 : 31-39. http://ejournal.unud.ac.id/abstrak/j-kimvol2-no1-gunawan.pdf (diakses tanggal 25 Januari 2011)

Harborne, J.B., 1996. Metode Fitokimia, Penuntun Cara Modern Menganalisis Tumbuhan (Phytochemical Methods). Diterjemahkan oleh Kosasih Padmawinata dan Iwang Soediro. Bandung. Penerbit ITB. 
Harmita, Radji, M., 2004.Analisis Hayati. Jakarta. Departemen Farmasi FMIPA Universitas Indonesia.

Jawetz, Melnick, Adelberg., 2001.Mikrobiologi Kedokteran Edisi.22. Penerjemah Bagian Mikrobiologi Fakultas Kedokteran Universitas Airlangga. Jakarta. Salemba Medika.

Kardinan, A., Kusuma, F. K., 2004. Sehat dengan Ramuan Tradisional, Meniran Penambah Daya Tahan Tubuh Alami. Jakarta. AgroMedia Pustaka.

Kemenkes RI., 2007. Keputusan Menteri Kesehatan Republik Indonesia, Nomor 381/MENKES/ SK/III/2007, Tentang Kebijakan Obat Tradisional. http://www.litbang.depkes. go.id/download/regulasi/KMK_381_2007_ OBAT_TRADISIONAL.pdf_(diakses tanggal 5 Maret 2011)

Kemenkes RI., 2010. Peraturan Menteri Kesehatan Republik Indonesia, Nomor 003/MENKES/ PER/I/2010, Tentang Saintifikasi Jamu dalam Penelitian Berbasis Pelayanan Kesehatan. http://www.hukor.depkes.go.id/ up_prod_permenkes/PMK\%20No.003\%20 ttg\%20Saintifikasi\%20Jamu\%20Dalam\%20 Penelitian\%20Berbasis\%20Pelayanan\%20 Kesehatan.pdf (diakses tanggal 5 Maret 2011)
Mangunwardoyo, W., Cahyaningsih, E., Usia, T., 2008. Uji Aktivitas Antimikroba Ekstrak Herba Meniran (Phyllantus niruri Linn). Jurnal Obat Bahan Alam Vol.7 (1). Jakarta.

Panagan, A.T., Syarif, Nirwan, 2009. Uji Daya Hambat Asap Cair Hasil Pirolisis Kayu Pelawan (Tristania abavata) terhadap Bakteri Escherichia coli. Sumatera Selatan. Jurusan Kimia Fakultas MIPA, Universitas Sriwijaya.

Robinson, Trevor., 1995. Kandungan Organik Tumbuhan Tinggi (The Organic Constituents of Higher Plants). Diterjemahkan oleh Kosasih Padmawinata. Bandung. Penerbit ITB

Salni, Marisa, H., Mukti, R. W., 2011. Isolasi Senyawa Antibakteri dari Daun Jengkol (Pithecolobium lobatum Benth) dan Penentuan Nilai KHM-nya. Sumatera Selatan. Jurusan Biologi FMIPA, Universitas Sriwijaya. 